\title{
PERCEPÇÕES DE QUALIDADE DO SERVIÇO PÚBLICO
}

\section{THE QUALITY PERCEPTION OF THE PUBLIC SERVICE}

Recebido em 06.10.2014. Aprovado em 09.04.2015 Avaliado pelo sistema double blind review http://dx.doi.org/10.12712/rpca.v9i1.498

\section{Cristina Novaes}

crisbatistuta@yahoo.com.br

Fucape Business School - Boa Vista - ES - Brasil

\section{Sarah Lasso}

sarahvlasso@gmail.com

Fucape Business School - Boa Vista - ES - Brasil

\section{Emerson Wagner Mainardes}

emerson@fucape.br

Fucape Business School - Boa Vista - ES - Brasil

\section{Resumo}

Identificar o conceito de qualidade que mais influencia a percepção dos usuários a respeito da qualidade de um serviço público é o objetivo fundamental desta pesquisa. Após uma revisão literária sobre os conceitos de qualidade, foi realizada uma pesquisa descritiva do tipo survey, com uma abordagem quantitativa com uma amostra de 207 cidadãos. Os dados foram coletados por meio de um questionário contendo 21 afirmações acompanhadas de uma escala de concordância. $\mathrm{O}$ questionário foi formulado com cinco afirmações para cada conceito: Qualidade como Excelência, Qualidade como Valor, Qualidade como Conformação de Especificações e Qualidade como Superação das Expectativas dos Clientes. Para verificar a percepção geral do cidadão sobre um serviço público de qualidade, solicitou-se ao respondente que indicasse o quanto ele consegue perceber quando um serviço público é oferecido com qualidade. Após análise dos dados, os resultados evidenciam que a percepção do cidadão está relacionada ao conceito de Qualidade como Conformação de Especificações. 0 gestor público pode agir sobre as variáveis deste conceito para influenciar a percepção do cidadão sobre a qualidade de um serviço público.

Palavras chave: Qualidade. Cidadão. Gestão pública.

\section{Abstract}

To identify the quality concept the influence the most the citizen quality perception of the public service is the fundamental objective of this research. From the traditional concepts presented by the literature, a descriptive research like survey was made, with a quantitative approach on a 207 citizen sample. Data were collected by a questionnaire with 21 affirmatives with an agreement scale. The questionnaire was made with five affirmatives for each concept: Quality as Excellence, Quality as Value, Quality as Conformance to Specifications and Quality as the exceeding of the clients' expectations. To verify the general perception of citizens about public service quality, the respondent was asked to indicate how much he can perceive when a public service is offered with quality. After the data analyses, the results show that the citizen perception is related to the Quality as Conformance to Specifications. The public manage can act on the variables of this concept to influence the citizen perception over the public service quality.

Keyword: Quality. Citizen. Public management. 


\section{Introdução}

A qualidade tem se mostrado relevante para qualquer tipo de organização, incluindo-se as organizações públicas. Por causa de sua conhecida importância, o conceito de qualidade tem sido investigado no decorrer da história da administração e ainda continua sendo foco de interesse de organizações e investigadores (REEVES e BEDNAR, 1994), porém, definir qualidade é um exercício desafiador (MAINARDES e LOURENÇO, 2010).

A qualidade pode ser um diferencial competitivo de empresas públicas e privadas, e ela pode ser vista interna ou externamente à organização (MAINARDES e LOURENÇO, 2010). Quando é percebida internamente, pode auxiliar na eficiência da organização, minimiza o desperdício e aumenta a produtividade; quando visto externamente, possibilita manter clientes satisfeitos. Conforme Inojosa e Farran (1994) é preciso verificar como a qualidade está sendo absorvida pela sociedade e pelo serviço público e, ao mesmo tempo, se atualizando conforme se faz necessário.

Considerando a importância da qualidade para as organizações e focando especificamente nas organizações públicas, procura-se identificar o conceito de qualidade que mais influencia a percepção dos usuários quanto à qualidade de um serviço público, tendo por base os conceitos citados por Reeves e Bednar (1994): qualidade como excelência, qualidade como valor, qualidade como conformação de especificações, qualidade como atendimento e/ou superação das expectativas dos clientes.

A relevância deste estudo refere-se à existência de uma lacuna de pesquisa quanto a não predominância de um conceito de qualidade (MAINARDES e LOURENÇO, 2010) e ao entendimento do cidadão sobre a qualidade na prestação dos serviços públicos. Na área acadêmica, busca preencher uma lacuna sobre o tema, uma vez que identifica a percepção do cidadão quanto à qualidade na prestação do serviço público. Para a organização pública e a sociedade, é uma forma de compreender o cidadão quanto aos conceitos de qualidade adotados nos serviços públicos, permitindo ao gestor tomar decisões mais eficazes, realizar medidas e modificar processos que se fizerem necessários.

O estudo inicialmente definiu qualidade sob quatro conceitos: qualidade como excelência, qualidade como valor, qualidade como conformação de especificações e qualidade como atendimento e/ou superação das expectativas dos clientes. Na seqüência, tem-se a metodologia da pesquisa realizada. Em um terceiro momento, analisaram-se os dados coletados. Finalizou-se o estudo com as conclusões e recomendações.

\section{Conceitos de qualidade}

Definir conceitos é fundamental para realizar análises sobre qualidade. Pollit (1993, p.298) refere-se à presença do caráter ideológico: "a qualidade, assim como a virtude, tem uma forte conotação positiva, combinada com a enorme vantagem de que suas implicações reais continuam sendo sumamente vagas e imprecisas". Parasuraman et al (1985) acrescentam que a qualidade é uma construção mental, indescritível e sem definição. Sharma (2010) afirma que a interpretação do termo "qualidade" varia de indivíduo para indivíduo significando que a percepção da qualidade de um produto ou serviço, na perspectiva do cliente, pode ser diferente da do produtor. Por ser tão ampla e subjetiva, a qualidade é um construto que se define de forma diferente em cada organização (MISOCZKY e VIEIRA, 2001).

Percebe-se que o conceito de qualidade está relacionado a um dado momento histórico e é dinâmico. Desta forma, é necessário considerar que a missão organizacional e o seu projeto de qualidade estarão sujeitos a modificações conforme as mudanças do cenário político, econômico, social e cultural em que a organização está inserida, bem como seu campo de 
atuação. Tanto na área privada quanto na pública, os acordos e concessões prevêem que a qualidade esteja presente de maneira sutil e dinâmica. Neste sentido, mesmo que o processo tenha que ser modificado, não significa que o mesmo não tenha qualidade, apenas será adequado às necessidades do projeto. Também deve conter a possibilidade de se modificar com a mudança de valores, experiências e expectativas (POLLIT e BOUCKAERT, 1995).

Nesta pesquisa utilizaram-se os quatro conceitos de qualidade mais tradicionais na literatura de qualidade (REEVES e BEDNAR, 1994). Suas características e referências, para melhor visualização, foram sumarizados no Quadro 1 e são analisados na sequência.

\begin{tabular}{|c|c|c|}
\hline $\begin{array}{ll}\text { CONCEITOS } & \text { DE } \\
\text { QUALIDADE } & \end{array}$ & CARACTERÍSTICAS & ESTUDOS DE REFERÊNCIA \\
\hline $\begin{array}{ll}\text { Qualidade } & \text { como } \\
\text { Excelência } & \end{array}$ & $\begin{array}{l}\text { Conceito mais antigo: filosofia de ser o melhor, } \\
\text { superior a outros; } \\
\text { Conceito abstrato. }\end{array}$ & $\begin{array}{l}\text { Kitto em1951; Pirsig em } 1974 \text { e } \\
\text { 1992; Tuchman em 1980; Garvin } \\
\text { em 1984 e 1988. }\end{array}$ \\
\hline $\begin{array}{ll}\text { Qualidade } & \text { como } \\
\text { Valor } & \end{array}$ & $\begin{array}{l}\text { Segundo conceito surgido; trata da relação } \\
\text { preço X benefício; valorização de um produto } \\
\text { ou serviço depende de vários fatores } \\
\text { (conveniência, preço, atendimento de } \\
\text { necessidades, entre outros); } \\
\text { Conceito abstrato. }\end{array}$ & $\begin{array}{l}\text { Feigenbaum em 1951, 1961, 1983, } \\
\text { 1991; Abott em 1955; Curry em } \\
\text { 1985; Johnson em 1988. }\end{array}$ \\
\hline $\begin{array}{lr}\text { Qualidade } & \text { como } \\
\text { Conformação } & \text { de } \\
\text { Especificações } & \end{array}$ & $\begin{array}{l}\text { Conceito surgido com a manufatura; foca a } \\
\text { padronização de produtos; evita perdas e } \\
\text { desperdícios; qualidade controlável; é a } \\
\text { conformidade dos produtos comparada às } \\
\text { especificações do projeto; produto livre de } \\
\text { deficiências; foco em ferramentas de controle; } \\
\text { perfeição do produto; conceito objetivo e } \\
\text { quantificável. }\end{array}$ & $\begin{array}{l}\text { Shewhart em 1931; Levitt em } \\
\text { 1972; Schneider em 1973; Gilmore } \\
\text { em 1974; Crosby em 1979; Deming } \\
\text { em 1982 e 1986; Abernathy e } \\
\text { Corcoran em 1983; Chase e Tansik } \\
\text { em 1983; Hounshell em 1984; } \\
\text { Ishikawa em 1985 e 1986; Bowen e } \\
\text { Lawler em 1982; Yip em 1989; Iso } \\
\text { 9000: } 2005 \text { em 2005. }\end{array}$ \\
\hline $\begin{array}{l}\text { Qualidade como } \\
\text { Atendimento } \\
\text { e/ou Superação das } \\
\text { Expectativas dos } \\
\text { Clientes }\end{array}$ & $\begin{array}{l}\text { Conceito sofreu forte influência do setor de } \\
\text { serviços, sendo o mais recente; produto ou } \\
\text { serviço que melhor atende a condições dos } \\
\text { consumidores; características de produtos e } \\
\text { serviços que vão ao encontro das expectativas } \\
\text { dos consumidores; satisfação das expectativas } \\
\text { dos consumidores; conceito abstrato. }\end{array}$ & $\begin{array}{l}\text { Juran em 1951, 1962, 1974, 1988; } \\
\text { Judd em 1968; Shostack em 1977; } \\
\text { Lovelock em 1981; Oliver em 1981; } \\
\text { Grönroos em 1983 e 1990; Norman } \\
\text { em 1984; Parassuraman, Zeithaml } \\
\text { e Berry em 1985, 1988, 1991, } \\
\text { 1993; Buzzell e Galê em 1987; } \\
\text { Bitner em 1990; Carman em 1990; } \\
\text { Bolton e Drew em 1991 e Cronin e } \\
\text { Taylor em 1992. }\end{array}$ \\
\hline
\end{tabular}

Quadro 1: Conceitos de Qualidade

Fonte: adaptado de Mainardes e Lourenço (2010)

\section{Qualidade como Excelência}

A qualidade como excelência é aparentemente intuitiva, seu conceito é utilizado em diversas situações e nem sempre tem uma definição clara e objetiva (MAINARDES e LOURENÇO, 2010). A abordagem filosófica trata da qualidade como sinônimo de "excelência inata", ou seja, é percebida quando ocorre demonstração de elementos que apresentam características superiores (GARVIN, 1984).

O conceito de qualidade como excelência é conectado com a credibilidade. Conforme Rodríguez et al (2009), os cidadãos de uma região tem experiência com serviços oferecidos com o governo e, baseado em sua satisfação, tem percebida a qualidade de seu serviço. Assim, credibilidade é um fator importante para cidadãos e empresas a respeito das políticas do governo local. 
Sobre a qualidade como excelência, quanto ao atendimento ao público, a crítica realizada por Correa (1993) é que os países de Terceiro Mundo, por falta de discernimento quanto às verdadeiras prioridades, pela falta de recursos e também pela falta de respeito ao trabalho e ao homem, relegam ao segundo plano estas questões. Como exemplo, cita alguns itens que ficam a desejar sobre a excelência na qualidade nos serviços prestados: o número de pessoas que presta atendimento precisa ser proporcional à demanda; menciona que é comum ver pessoas sem formação nem experiência no trato com o público-cliente; fala de chefes sem conhecimento que se esconde por detrás da equipe ocupando-as com trabalhos internos e deixando o cliente numa espera interminável.

Nos fundamentos do Programa Nacional de Gestão Pública e Desburocratização (Gespública), orientando a gestão por resultados com foco no Cidadão (BRASIL, 2009, p.7), o primeiro fundamento trata da excelência dirigida ao cidadão, ou seja, a atenção deve ser prioritária ao cidadão e à sociedade; demonstra uma vontade de prestar um atendimento de excelência para cada demanda do cidadão.

\section{Qualidade como Valor}

Conforme ponto de vista a qualidade como valor, um produto de qualidade é aquele que apresenta desempenho a um preço e custos aceitáveis (GARVIN, 1984). A durabilidade, para este autor, é uma característica que possibilita a medida do tempo de vida do produto, ou seja, possui dimensões econômicas e técnicas porque define a quantidade de uso do produto antes que ele se deteriore.

A função da administração pública é prover à sociedade os serviços que necessita. Enquanto isso, os cidadãos, que efetuam pagamento de impostos, taxas e contribuições, esperam, em contrapartida, receber serviços públicos de qualidade equivalente à contribuição feita (CARVALHO e TONET, 1994).

Rodríguez et al (2009) afirmam que a satisfação com o serviço não está relacionada apenas com o atendimento de suas necessidades. A situação política, taxas, ou outras situações pessoais, afetam a percepção do cidadão a respeito da qualidade do serviço oferecido.

Para Abreu (1994), o consumidor faz julgamento de valor comparando o sacrifício para adquirir o produto e a qualidade deste produto. Quando ele percebe a utilidade maior que o preço, a percepção de valor é positiva, e quando a percepção de sacrifício for maior, haverá uma percepção de valor negativa.

Cabe à organização pública oferecer serviços públicos para os cidadãos, direcionando o uso dos impostos recolhidos para atender demandas públicas. Um dos princípios do artigo 37 da Constituição Federal diz que o serviço público tem que ser produzido com eficiência, significando fazer o que é preciso com o máximo de qualidade ao menor custo possível (ESESP, 2008)

O objetivo principal da maioria das organizações do setor público é o de proporcionar um benefício social dentro de um orçamento limitado e reduzir custos (DEWHIRST et al, 1999). Para Carvalho e Tonet (1994), procedimentos arcaicos precisam ser substituídos por uma abordagem de solução de problemas. Como exemplos, citam o excesso de controles do processo e inexistência de avaliações de resultados; sonegação; morosidade; insuficiência de serviços básicos prestados pelo governo; baixa qualidade em todos os serviços prestados. Em contrapartida, algumas soluções para adotar no serviço público: participação, alargamento e enriquecimento de funções, delegação e responsabilização por novas tarefas, acompanhamento e discussão sobre o desempenho, definição conjunta de objetivos de trabalho, treinamento para a tarefa e desenvolvimento de potencial. 
Nos fundamentos do Programa Nacional de Gestão Pública e Desburocratização (Gespública), orientando a gestão por resultados com foco no Cidadão (BRASIL, 2009, p.7), a gestão baseada em processos e informações se refere ao conjunto de atividades inter-relacionadas ou interativas que transforma insumos (entradas) em serviços (saídas) com alto valor agregado e explica a vontade da organização pública em realizar com eficiência os serviços que são de sua responsabilidade.

\section{Qualidade como Conformação de Especificações}

A conformidade significa o grau em que o projeto de um produto e as características operacionais são realizadas de acordo com os padrões pré-estabelecidos (GARVIN, 1984). Para Tellis e Gaeth (1990), qualidade é o desempenho do produto de acordo com as especificações. Para este conceito a qualidade é controlável, é padronizada, ou seja, a conformidade dos produtos é comparada às especificações do projeto. Existem ferramentas de controle com a finalidade de garantir um produto livre de deficiências, evitar desperdícios e garantir a perfeição do produto (MAINARDES e LOURENÇO, 2010).

O principal objetivo na padronização do produto deve ser a satisfação total do cliente (ISHIKAWA, 1984), ou seja, devem-se captar as necessidades do cliente e transformá-las num projeto (CAMPOS,1991).

A qualidade como conformação de requisitos pode estar conectada a prestação de serviços como, por exemplo, transporte público, por que o processo tem um papel importante na determinação da qualidade do resultado (GHOBADIAN et al, 1994). 0 cliente percebe o que foi proposto com o que foi oferecido e ainda verifica a qualidade do que está sendo realizado.

A Gespública (BRASIL, 2009, p.7) apresenta quatro fundamentos que tratam de questões voltadas a implementar melhorias para atender melhor o cidadão: aprendizado organizacional, ou seja, o aprendizado deve ser internalizado na cultura organizacional, tornando-se parte do trabalho diário em quaisquer das suas atividades; a agilidade, que é a antecipação e resposta rápida às mudanças do ambiente; o foco em resultados, cujo resultado é a materialização de todo esforço da organização, e, por fim, a inovação, que é fazer mudanças significativas para melhorar os processos e serviços.

Pode-se dizer que para alcançar a qualidade na organização pública, é necessário realizar projetos focados na padronização de ações, que objetivem providências que demonstrem consideração com o cidadão. Corrêa (1993, p.120) afirma que existência de um

"ambiente limpo, pessoal bem-humorado, ordenação do atendimento, triagem efetiva e atenção eficiente e responsável para os casos mais urgentes, sistema que facilite o acesso do cliente ao serviço; simplificação do preenchimento de formulários; simplificação e redução do número de contatos com o público para satisfazer exigências burocráticas; sistema rápido e dinâmico de informações; sistema de treinamento de chefias e do pessoal de atendimento, redução do tempo de atendimento pela eliminação de espera inútil e desnecessária, melhoria do sistema de contato e informação (...)"

Neste sentido, a qualidade pode proporcionar a eficiência dos processos e a eficácia nos resultados.

\section{Qualidade como Atendimento e/ou Superação das Expectativas dos Clientes}

Este conceito é o mais novo e sofreu forte influência do setor de serviços (quadro 1). Segundo Parasuraman et al (1985), pesquisadores e gestores da área de serviços concluíram que a qualidade em serviço envolve a comparação das expectativas com o desempenho. Segundo Bitner (1990), cada consumidor tem expectativas sobre como cada serviço será entregue. Estas expectativas são comparadas com as percepções do serviço quando ele é entregue. Se as expectativas são maiores que o desempenho, resulta-se na não satisfação, porém quando as 
expectativas são encontradas, ou quando o desempenho é superado, a satisfação é encontrada.

Carvalho e Tonet (1994) afirmam que a expectativa da sociedade com relação aos serviços recebidos da organização pública tem se modificado. 0 sentimento de cidadania tem levado as pessoas a abandonarem a posição passiva em relação às ações do governo e a se organizarem para exigir maior eficiência/eficácia da administração pública. A população pede mais e melhores serviços públicos e cobra melhor gestão dos recursos e do patrimônio públicos. Para tanto, se faz necessária a adoção de programas governamentais voltados para a melhoria das agências prestadoras desses serviços.

A qualidade como superação das expectativas dos clientes é um conceito abstrato, pois trata da satisfação da expectativa do consumidor (MAINARDES e LOURENÇO, 2010). Os consumidores possuem expectativas diferentes porque possuem diferentes necessidades e desejos (GARVIN, 1984).

Com relação ao atendimento das expectativas do cidadão a respeito do serviço público, há a necessidade da melhoria do atendimento, colocando o cidadão, assim como no setor privado, no centro das atenções (MWITA, 2000).

Conforme o fundamento visão de futuro da Gespública (BRASIL, 2009, p.7), que significa a busca da excelência nas organizações públicas, que é diretamente relacionada à sua capacidade de estabelecer um estado futuro desejado, que dê coerência ao processo decisório e que permita à organização antecipar-se às novas necessidades e expectativas do cidadão e da sociedade, traduz o pensamento da qualidade que supera a expectativa do cliente quando antecipa sua necessidade.

\section{Metodologia}

O método escolhido para responder o objetivo da pesquisa foi o método descritivo do tipo survey. Foi realizado um corte transversal, objetivando analisar os dados no momento atual (HAIR et al, 2005). A população desta pesquisa é abrangente, pois inclui cidadãos que utilizam ou são usuários em potencial do serviço público e pagam impostos. A amostra foi escolhida por conveniência, sendo não probabilística. A amostragem não probabilística se mostrou mais adequada porque a qualidade é um conceito abstrato e medidas de percepção dificilmente permitem generalizações. No caso desse estudo esta estrutura de amostragem trouxe relevantes evidências da percepção dos cidadãos sobre o significado para ele do que seja um serviço público de qualidade. Assim, uma amostra final formada por 207 respondentes que se consideram serem cidadãos que pagam impostos e utilizam serviços públicos.

Utilizou-se, para coleta de dados, um questionário contendo 21 afirmações a respeito dos quatro conceitos de qualidade adaptados de Mainardes e Lourenço (2010). As afirmações foram acompanhadas de uma escala de concordância, sendo elas: 1 - discordo totalmente, 2 - discordo parcialmente, 3 - indiferente, 4 - concordo parcialmente, 5 - concordo totalmente..

O questionário foi formulado com cinco afirmações para cada conceito: As afirmações de número 2 ao número 6 referem-se aos conceitos de Qualidade como Excelência, de 7 a 11 referem-se à Qualidade como Valor, de 12 a 16 são afirmações sobre o conceito de Qualidade como Conformação de Especificações, finalizando as afirmações de 17 a 21, referentes aos conceitos de Qualidade como Superação das Expectativas dos Clientes. Foi realizada uma afirmação geral: "Eu sei identificar quando um serviço público é oferecido com qualidade", sendo esta a variável dependente que no questionário é a afirmação 1. As afirmações, na íntegra, pode ser vistas no quadro 2. Para identificar o perfil dos respondentes da amostra foi realizado um questionário complementar contendo perguntas sobre idade, renda, escolaridade, freqüência do uso do serviço público e tipo de serviço público mais utilizado. 
Depois de construído, um pré-teste do questionário da pesquisa foi realizado com cinco respondentes, que não identificaram problemas no mesmo, validando seu conteúdo. Posteriormente, o questionário foi disponibilizado para coleta de dados através da plataforma online GoogleDocs. Utilizou-se como ferramenta de coleta das respostas um computador e um notebook conectados na internet. 0 questionário ficou disponível de 12/08/2013 a 23/08/2013. Também foi enviado pelo email e facebook. Foi realizado um método de pesquisa conhecido como "bola de neve", onde se encaminha o questionário por rede social e solicita-se que este seja compartilhado com outras pessoas.

\begin{tabular}{|c|c|c|}
\hline VARIÁVEIS & CONCEITO E AFIRMAÇÕES & AUTORES \\
\hline & Qualidade como Excelência & \multirow{6}{*}{$\begin{array}{l}\text { Garvin (1984), } \\
\text { Mainardes } \\
\text { Lourenço } \\
(2010), \\
\text { Rodríguez et al } \\
\text { (2009), Corrêa } \\
(1993), \quad \text { Brasil } \\
(2009)\end{array}$} \\
\hline $\mathrm{X} 1$ & $\begin{array}{l}\text { Considero serviço público de excelência aquele serviço público que } \\
\text { sempre resolve o que preciso. }\end{array}$ & \\
\hline $\mathrm{X} 2$ & $\begin{array}{l}\text { Considero serviço público de excelência aquele serviço público que } \\
\text { responde corretamente o que preciso saber }\end{array}$ & \\
\hline $\mathrm{X} 3$ & $\begin{array}{l}\text { Considero serviço público de excelência aquele serviço público que } \\
\text { respeita os meus direitos. }\end{array}$ & \\
\hline $\mathrm{X} 4$ & $\begin{array}{l}\text { Considero serviço público de excelência aquele serviço público que o } \\
\text { atendimento é sempre perfeito. }\end{array}$ & \\
\hline \multirow[t]{2}{*}{$\mathrm{X} 5$} & $\begin{array}{l}\text { Considero serviço público de excelência aquele serviço público onde } \\
\text { existem pessoas suficientes para prestar atendimento e resolver os } \\
\text { problemas. }\end{array}$ & \\
\hline & Qualidade como Valor & \\
\hline $\mathrm{X} 6$ & $\begin{array}{l}\text { Considero serviço público de qualidade aquele serviço público onde as } \\
\text { necessidades básicas, como saúde, educação, segurança, são atendidos. }\end{array}$ & \multirow{5}{*}{ 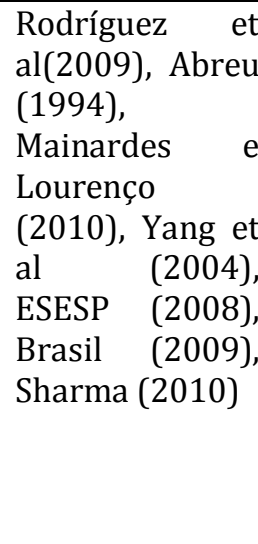 } \\
\hline $\mathrm{X} 7$ & $\begin{array}{l}\text { Considero serviço público de qualidade aquele serviço público onde os } \\
\text { serviços estão sempre disponíveis quando preciso. }\end{array}$ & \\
\hline $\mathrm{X} 8$ & $\begin{array}{l}\text { Considero serviço público de qualidade aquele serviço público onde os } \\
\text { impostos são revertidos em benefício da população. }\end{array}$ & \\
\hline $\mathrm{X} 9$ & $\begin{array}{l}\text { Considero serviço público de qualidade aquele serviço público que } \\
\text { demonstra se esforçar para resolver os problemas da população. }\end{array}$ & \\
\hline \multirow[t]{2}{*}{$\mathrm{X} 10$} & $\begin{array}{l}\text { Considero serviço público de qualidade aquele serviço público onde os } \\
\text { profissionais de qualquer hierarquia, são competentes e comprometidos } \\
\text { com os serviços. }\end{array}$ & \\
\hline & Qualidade como Conformação de Especificações & \\
\hline $\mathrm{X} 11$ & $\begin{array}{l}\text { Considero serviço público de qualidade aquele serviço público que } \\
\text { cumpre os princípios da lei contidos no artigo } 37 \text { da Constituição } \\
\text { Federal: legalidade (obediência a lei), impessoalidade (não faz acepção } \\
\text { de pessoas), moralidade (valores de aceitação pública), publicidade } \\
\text { (ser transparente) e eficiência (fazer o que precisa ser feito com a } \\
\text { máxima qualidade e menor custo possível). }\end{array}$ & \multirow{2}{*}{$\begin{array}{l}\text { Garvin (1984), } \\
\text { Tellis } \\
\text { Gaeth(1990), } \\
\text { Deming (1990), } \\
\text { Ishikawa(1984), } \\
\text { Campos (1999), } \\
\text { Mainardes } \\
\text { Lourenço } \\
(2010)\end{array}$} \\
\hline $\mathrm{X} 12$ & $\begin{array}{l}\text { Considero serviço público de qualidade aquele serviço público onde os } \\
\text { serviços são padronizados: qualquer servidor oferece a mesma } \\
\text { prestação de serviço e com a mesma eficiência. }\end{array}$ & \\
\hline $\mathrm{X} 13$ & $\begin{array}{l}\text { Considero serviço público de qualidade aquele serviço público onde os } \\
\text { processos são melhorados a cada avanço tecnológico. }\end{array}$ & \multirow{2}{*}{$\begin{array}{l}\text { Ghobadian } \\
\text { Jones } \\
\text { (1994),Carvalho } \\
\text { e Tonet (2009), } \\
\text { Brasil (2009), }\end{array}$} \\
\hline $\mathrm{X} 14$ & $\begin{array}{l}\text { Considero serviço público de qualidade aquele serviço público que } \\
\text { cumpre padrões de qualidade como: cumprimento de prazos, horário de }\end{array}$ & \\
\hline
\end{tabular}




\begin{tabular}{|c|c|c|}
\hline & $\begin{array}{l}\text { funcionamento, organização, limpeza, identificação das instalações e dos } \\
\text { funcionários, comunicação clara com o cidadão, atenção e cortesia com o } \\
\text { usuário. }\end{array}$ & Corrêa (1993) \\
\hline \multirow[t]{2}{*}{$\mathrm{X} 15$} & $\begin{array}{l}\text { Considero serviço público de qualidade aquele serviço público onde os } \\
\text { servidores são bem treinadas. }\end{array}$ & \\
\hline & Qualidade como Superação das Expectativas do Cliente & \\
\hline $\mathrm{X} 16$ & $\begin{array}{l}\text { Considero serviço público de qualidade aquele serviço público que } \\
\text { supera minhas expectativas. }\end{array}$ & \multirow{5}{*}{$\begin{array}{l}\text { Parasuraman et } \\
\text { al (1985), } \\
\text { Bolton e Drew } \\
(1991), \\
\text { Mainardes e } \\
\text { Lourenço } \\
(2010), \quad \text { Garvin } \\
(1984), \quad \text { Mwita } \\
(2000), \quad \text { Brasil } \\
(2009)\end{array}$} \\
\hline $\mathrm{X} 17$ & $\begin{array}{l}\text { Considero serviço público de qualidade aquele serviço público que } \\
\text { considera as minhas condições particulares para prestar o atendimento } \\
\text { (cadeirante, analfabeto, acamado, etc) }\end{array}$ & \\
\hline $\mathrm{X} 18$ & $\begin{array}{l}\text { Considero serviço público de qualidade aquele serviço público onde a } \\
\text { minha necessidade é mais importante que a burocracia. }\end{array}$ & \\
\hline $\mathrm{X} 19$ & $\begin{array}{l}\text { Considero serviço público de qualidade aquele serviço público onde não } \\
\text { existem barreiras em atender o cidadão. }\end{array}$ & \\
\hline $\mathrm{X} 20$ & $\begin{array}{l}\text { Considero serviço público de qualidade aquele serviço público onde cada } \\
\text { serviço é realizado de maneira especial. }\end{array}$ & \\
\hline
\end{tabular}

Quadro 2: Variáveis independentes

Fonte: elaboração própria

Após a coleta de dados, foram realizadas as seguintes análises: Caracterização da Amostra, Estatística Descritiva e Regressão Múltipla Linear. A Caracterização da Amostra foi utilizada para conhecer as características dos respondentes do estudo, como idade, renda, escolaridade, freqüência do uso do serviço público e tipo de serviço público mais utilizado. Na Estatística Descritiva foi considerada a média e o desvio padrão das respostas da pesquisa, analisando as percepções médias dos respondentes e eventuais consensos ou não (HAIR et al, 2005). Para alcançar o objetivo principal deste trabalho, foi utilizada a Regressão Múltipla Linear para verificar a influência dos indicadores sobre a variável dependente, pois este modelo é utilizado para mais de uma variável independente (HAIR et al, 2005).

As variáveis independentes foram apresentadas no quadro 2 e foram codificadas de X1 a X20: X1 a X5 são as afirmações realizadas a respeito do conceito Qualidade como Excelência; X6 a X10 o conceito Qualidade como Valor; X11 a X15 relativo ao conceito Qualidade como Conformação de Especificações; e X16 a X20 referem-se ao conceito Qualidade como Superação das Expectativas do Cliente. A variável dependente foi codificada como "Y", sendo a afirmação "Eu sei identificar quando um serviço público é oferecido com qualidade".

\section{Análise de dados \\ Caracterização da Amostra}

Realizou-se uma análise das características dos 207 respondentes, que está sumarizada na Tabela 1.

\begin{tabular}{|l|l|c|}
\hline CARACTERÍSTICA & CLASSIFICAÇÃO & PERCENTUAL \\
\hline \multirow{4}{*}{$\begin{array}{l}\text { Frequência de utilização do } \\
\text { serviço público }\end{array}$} & Todo mês & 63,77 \\
\cline { 2 - 3 } & Bimensal & 8,70 \\
\cline { 2 - 3 } & Trimestral & 4,83 \\
\cline { 2 - 3 } & Semestral & 16,43 \\
\cline { 2 - 3 } & Ocasional & 6,28 \\
\hline \multirow{2}{*}{} & 15 a 25 & 28,66 \\
\cline { 2 - 3 } & 26 a 35 & 28,02 \\
\hline
\end{tabular}


Emerson Wagner Mainardes, Sarah Lasso e Cristina Novaes

\begin{tabular}{|c|c|c|}
\hline \multirow[t]{3}{*}{ Idade } & 36 a 45 & 27,05 \\
\hline & 46 a 55 & 24,64 \\
\hline & Acima 56 & 10,63 \\
\hline \multirow{5}{*}{ Renda Mensal } & $0-\mathrm{R} \$ 500,00$ & 5,80 \\
\hline & $\mathrm{R} \$ 500,01-\mathrm{R} \$ 2.000,00$ & 22,22 \\
\hline & $\mathrm{R} \$ 2.000,01-\mathrm{R} \$ 5.000,00$ & 35,27 \\
\hline & $\mathrm{R} \$ 5.000,01-\mathrm{R} \$ 8.000,00$ & 18,84 \\
\hline & Acima de $\mathrm{R} \$ 8.000,01$ & 17,87 \\
\hline \multirow[t]{6}{*}{ Escolaridade } & Ensino médio & 12,56 \\
\hline & Graduação & 35,75 \\
\hline & Especialização & 32,37 \\
\hline & Mestrado & 13,04 \\
\hline & Doutorado & 4,35 \\
\hline & Outro & 1,93 \\
\hline \multirow{6}{*}{$\begin{array}{l}\text { Tipo serviço } \\
\text { público } \\
\text { utilizado }\end{array}$} & Administrativo (previdência, banco, licenciamento, etc) & 39,13 \\
\hline & Educação & 11,59 \\
\hline & Transporte & 20,28 \\
\hline & Saúde & 15,94 \\
\hline & Segurança & 7,24 \\
\hline & Outro & 5,79 \\
\hline
\end{tabular}

Tabela : Caracterização da Amostra

Fonte: dados da pesquisa

Analisando a tabela 1, é possível afirmar que a maior parte dos respondentes está em idade economicamente ativa (nesta pesquisa as idades entre 26 e 55 anos representam $79,71 \%$ dos respondentes da amostra), é usuário mensal de serviços públicos (63,77\%), tem renda relativamente baixa (entre $\mathrm{R} \$ 500,00$ e $\mathrm{R} \$ 5.000,00$, sendo que talvez por isso seja um utilizador mais frequente dos serviços públicos), mas tem alta escolaridade (quase $90 \%$ da amostra tem escolaridade superior a graduação e possivelmente por isso consiga avaliar melhor a qualidade de um serviço público e distinguir o que é melhor ou pior).

Considerando isto, pode-se inferir que a amostra obtida mostra-se adequada para responder aos objetivos da investigação. Em resumo, é o usuário frequente de serviços públicos quem pode melhor perceber a qualidade do mesmo.

\section{Estatística Descritiva}

Na Estatística Descritiva, foi analisada cada variável, observando sua média e seu desvio padrão. Para melhor visualização, os resultados estão expostos na Tabela 2. 


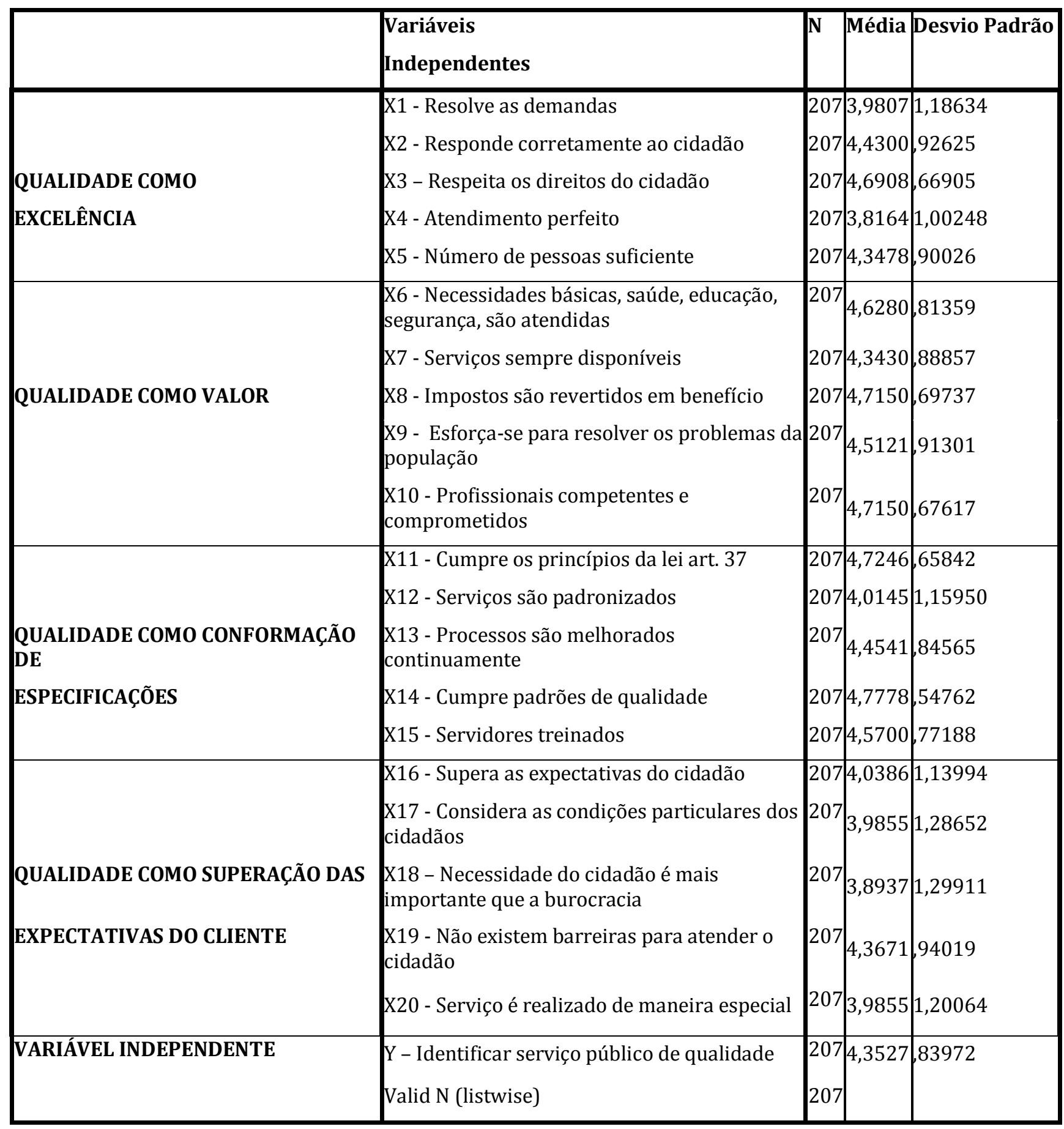

Tabela 2: Estatística Descritiva

Fonte: dados da pesquisa

A respeito da variável dependente "Y", a afirmativa "eu sei identificar quando um serviço público é oferecido com alta qualidade", os índices encontrados foram: discordam totalmente como também discordam parcialmente foi representado cada um por 1,44\% dos respondentes; os que responderam ser indiferentes representaram 10,62\%; o percentual de 33,33\% ficou para os que concordam parcialmente e a maioria respondeu que concorda totalmente sendo representados por $53,14 \%$ dos respondentes. Somando-se os dois últimos percentuais, o resultado encontrado nesta pesquisa a respeito da variável Y leva a constatar que $86,47 \%$ dos respondentes afirmaram que sabem identificar quando um serviço público é oferecido com alta qualidade. 
É possível notar na Tabela 2 que todas as médias são altas, o que dá a entender que os respondentes concordam com as afirmativas relacionadas ao reconhecimento da qualidade em serviços públicos.

No conceito Qualidade por Excelência, as maiores médias foram encontradas nas variáveis X2, relacionada ao indicador de qualidade do serviço público que "responde corretamente ao cidadão", que obteve uma média de 4,43 com desvio padrão 0,92. Outra variável, X3, referente ao atendimento de excelência que "respeita os direitos do cidadão", é o indicador que obteve a média mais alta $(4,69)$ e o desvio padrão mais baixo $(0,66)$. Ainda sobre as médias mais altas, $o$ indicador X5, referente ao serviço público onde "sempre existem pessoas suficientes para prestar atendimento e resolver problemas", obteve uma média acima de 4,0 $(4,34)$ e o desvio padrão baixo de 0,9. As menores médias referem-se às variáveis X1 e X4. Em X1, cuja afirmação diz respeito a "resolver as demandas", a média encontrada foi 3,98 e desvio padrão 1,18. A variável X4, relacionada ao "atendimento perfeito", obteve média de 3,81 e desvio padrão 1,00. De modo geral, todas as variáveis deste conceito apresentaram médias altas e desvios padrão relativamente baixos, significando que há um alto nível de concordância dos respondentes a respeito das afirmações apresentadas. As maiores médias deste conceito foram X2 e X3, que estão conectadas com responder corretamente e respeitar direitos. Ambas estão de acordo com Rodríguez et al (2009), que afirma que a credibilidade é um fator importante para os cidadãos, uma vez que responder corretamente e respeitar o usuário podem ser ligados à credibilidade e à qualidade como excelência.

Corrêa (1993), na sua crítica sobre a falta de respeito do serviço público ao trabalho e ao homem, citou que estes ficam a desejar, coerente como os resultados analisados, pois é possível verificar que respeito a direitos é reconhecido pelo cidadão como um atendimento de excelência do serviço público.

Os resultados deste conceito podem ser conectados ao Programa Nacional de Gestão Pública e Desburocratização - Gespública (BRASIL, 2009) uma vez que todas as variáveis tratam da excelência dirigida ao cidadão. Demonstra que o governo federal, através deste programa, reflete o pensamento do cidadão, pois o que os respondentes consideraram importante é citado como foco na Gespública.

Ao observar o conceito Qualidade como Valor, percebe-se que todos os indicadores obtiveram médias altas, acima de 4,3, e desvios padrão baixos, o que indica homogeneidade das percepções da amostra sobre este conceito. As maiores médias foram X8 - "impostos são revertidos em benefício" e X10 - "profissionais competentes e comprometidos", cada um com 4,71 de média e desvio padrão 0,69 e 0,67 respectivamente. Compreende-se, portanto, que existe um alto nível de concordância entre os respondentes sobre estas variáveis. A afirmativa de X8 da pesquisa concorda com Carvalho e Tonet (1994) e com Rodríeguez et al (2009), que afirmam que os cidadãos fazem pagamento de impostos e esperam receber produtos e serviços de qualidade. A variável X10 concorda com os autores Carvalho e Tonet (1994), que abordam a importância do treinamento para a tarefa e o desenvolvimento das competências como algumas das soluções para o serviço público.

Sobre este conceito, pode-se analisar que se o governo quer que o cidadão perceba valor no serviço, ele precisa preocupar-se com as afirmativas deste conceito. Todas as médias foram acima de 4,3 e todos os desvios padrão foram baixos. Isto significa que estas variáveis foram confirmadas pelos respondentes e há pouca discordância entre eles.

0 terceiro conceito, relacionado à Qualidade como Conformação de Especificação, a menor média foi X12 $(4,01)$ e com desvio padrão relativamente alto $(1,15)$, significando que há alguma heterogeneidade. Este indicador refere-se aos "serviços públicos que são padronizados: 
qualquer servidor oferece a mesma prestação de serviços e com a mesma eficiência." A média mais alta deste conceito foi X14, que se refere ao "serviço público que cumpre padrões de qualidade como: cumprimento de prazos, horário de funcionamento, organização, limpeza, identificação das instalações e dos funcionários, comunicação clara com o cidadão, atenção e cortesia com o usuário". 0 desvio padrão neste indicador foi o mais baixo do conceito, com valor de 0,54, significando uma maior homogeneidade entre os respondentes da amostra. Este conceito, especificamente as variáveis X12 e X14, são conectados com Garvin (1984), que afirma que as atividades devem ser realizadas de acordo com padrões de qualidade pré estabelecidos. No serviço público, referem-se aos padrões de qualidade estabelecidos pelo decreto 3507 pelos órgãos e pelas entidades da Administração Pública Federal, ora replicados pelos órgãos estaduais e municipais (ESESP, 2008).

A partir dos resultados analisados pode-se afirmar que se o governo deseja que o cidadão perceba que o serviço segue padrões especificados, ele precisa cumprir com eficiência o que foi afirmado a respeito deste conceito, uma vez que todas as médias das variáveis foram altas. Isto demonstra que todas estas variáveis foram avaliadas como importantes pelos respondentes.

Ainda sobre a análise da Estatística Descritiva, o último conceito analisado é Qualidade como Superação das Expectativas dos Clientes, que obteve média a partir de 3,89. Os indicadores X16 - "supera as expectativas do cidadão e X19 - "não existem barreiras para atender o cidadão", tiveram as maiores médias, 4,03 e 4,36 respectivamente. As menores médias foram as variáveis X17, X18 e X20, sendo X17 referente a "considera as condições particulares dos cidadãos", X18, "necessidade do cidadão é mais importante que a burocracia", e X20 "serviço é realizado de maneira especial." Mesmo assim, todas as variáveis tiveram médias consideradas acima da indiferença quanto ao conceito, ou seja, com médias acima de 3,89.

Neste conceito, todas as variáveis da pesquisa podem se conectar com Garvin (1984), que afirma que os consumidores possuem expectativas, necessidades e desejos diferentes. Mwita (2000) diz que o cidadão deve ser o centro das atenções, ou seja, esta afirmação vai ao encontro de X20 -"serviço é realizado de maneira especial" e X18 - "minha necessidade é mais importante que a burocracia". Estas variáveis concordam com o Programa Nacional de Gestão Pública e Desburocratização - Gespública, que é orientado para o cidadão (BRASIL, 2009).

Analisando todas as médias das variáveis, é possível afirmar que os respondentes consideram importantes todas as variáveis apresentadas nesta pesquisa. Porém, prover ao cidadão de todas as ações que formam as variáveis demanda tempo e variados recursos (recursos humanos, financeiros, materiais, tecnológicos, patrimoniais), sendo muito difícil gerir tudo o que foi apresentado aqui. Portanto, torna-se necessária uma análise mais profunda para identificar as variáveis que realmente influenciam as percepções de qualidade do serviço público por parte do cidadão.

\section{Regressão Múltipla}

Com a finalidade de verificar quais variáveis independentes (afirmações referentes a cada conceito) afetam significativamente a variável dependente "Y", a afirmativa "Eu sei identificar quando um serviço público é oferecido com alta qualidade", foi realizada a regressão linear múltipla (Tabelas 3 e 4).

Analisando as tabelas 3 e 4 obtida com a regressão dos indicadores do modelo proposto, tem-se as variáveis X15 - Servidores treinadas e X11 - Cumpre os princípios da lei artigo 37 como significativas para influenciar a variável dependente. 0 poder de explicação do modelo, conforme se obteve em R2 ajustado, é de 0,186, o que significa que estas variáveis independentes influenciam a variável dependente em 18,6\%. 


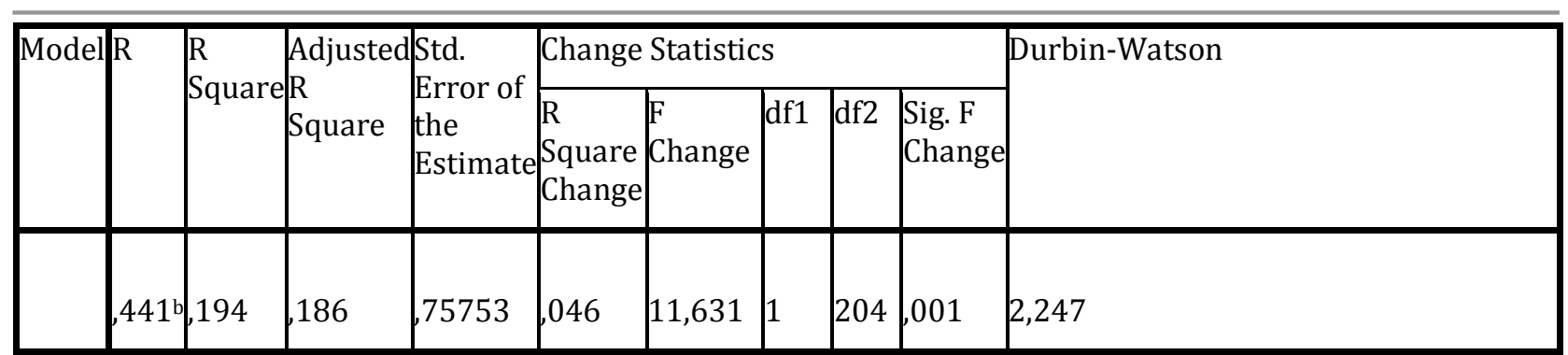

a. Predictors: (Constant), X15, X11

b. Dependent Variable: Y

Método de estimação: Stepwise

Testes de validez:

ANOVA: significativo

Teste de Aleatoriedade: Suporta a hipótese de aleatoriedade

Teste de Aderência Kolmogorov-Smirnov: Suporta hipótese de aderência a distribuição normal

Teste de Homocedasticidade: Suporta a hipótese de homocedasticidade

Tabela 3: Regressão Múltipla

Fonte: dados da pesquisa

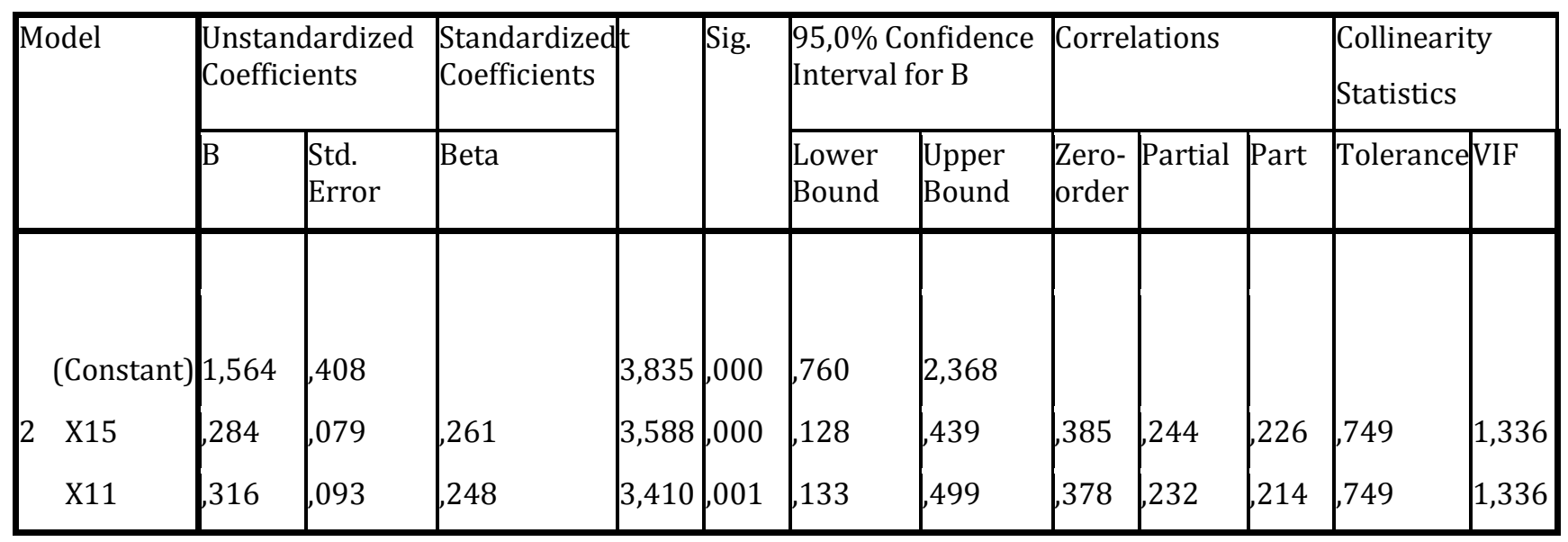

a. Dependent Variable: $\mathrm{Y}$

Tabela 4: Coeficientes da Regressão

Fonte: dados da pesquisa

Verificando o teste de validez ANOVA, o modelo é significativo a 1\%. 0 indicador X11 e o indicador X15 referem-se ao conceito Qualidade como Conformação de Especificações. Outras variáveis, que não foram contempladas nesta pesquisa, afetam a variável independente "Eu sei identificar quando um serviço público é oferecido com qualidade", em 81,4\%.

A respeito da variável independente $\mathrm{X} 11$, "considero serviço público de qualidade aquele serviço público que cumpre os princípios da lei contidos no artigo 37 da Constituição Federal: legalidade (obediência a lei), impessoalidade (não faz acepção de pessoas), moralidade (valores de aceitação pública), publicidade (ser transparente) e eficiência (fazer o que precisa ser feito com a máxima qualidade e menor custo possível)", refere-se ao estado de direito da administração pública. Diz respeito ao que a organização pública e o servidor público precisam, antes de qualquer coisa, aplicar no seu local de trabalho.

O Programa Nacional de Gestão Pública e Desburocratização - Gespública, possui objetivos claros, "com ênfase na produção de resultados positivos para a sociedade, na otimização de 
custos operacionais, na motivação e participação dos servidores, na delegação, na racionalidade no modo de fazer, na definição clara de objetivos e no controle dos resultados" (ESESP, 2008, p. 2).

Esta análise quer enfatizar o conceito de Qualidade como Conformação de Especificações, que diz que as atividades devem ser realizadas de acordo com padrões pré-estabelecidos (GARVIN, 1984). A Constituição Federal, por meio do artigo 37, constituiu uma lei que traduz qual o padrão deve ser seguido pela organização pública. Em resumo, cumprir as exigências da lei tendem a resultar em uma percepção de serviço público de alta qualidade pelo cidadão.

Outro aspecto a ser analisado desta variável X11 é a cultura da organização quanto ao cumprimento do que foi estabelecido. É por meio da cultura organizacional que se aprende como agir de acordo com o que é demandado da missão da organização (CARVALHO e TONET, 1994). A comunicação formal é um dos elementos da cultura, que no artigo 37 é um princípio que é denominado publicidade. Outro princípio, a moralidade, que significa valores de aceitação pública, também é um elemento da cultura. Carvalho e Tonet (1994, p.22) dizem que valores tratam do que "a organização considera importante preservar ou realizar para alcançar ou manter a imagem e o nível de sucesso desejado."

A variável X15, cuja afirmativa é "considero serviço público de qualidade aquele serviço público onde os servidores são bem treinados", aponta uma meta para os gestores neste conjunto de afirmativas que traduzem a qualidade.

Treinar um profissional permite o desenvolvimento de algumas habilidades imprescindíveis para o exercício de um serviço de qualidade. Corrêa (1993) considera que o treinamento das chefias e do pessoal do atendimento como uma complexa providência a ser tomada pela organização pública. Carvalho e Tonet (1994, p. 137), afirmam que o desenvolvimento das pessoas precisa fazer parte de um conjunto de ações que objetivem "viabilizar a introdução de práticas de trabalho mais eficientes e de modelos de gestão mais democráticos no serviço público."

A Gespública (BRASIL, 2009, p. 7), em seus fundamentos para melhorar o atendimento ao cidadão, fala sobre o aprendizado organizacional, que significa internalizar na cultura da organização o aprendizado constante. Outro fundamento, não menos importante, é a inovação com a finalidade de melhorar os processos e os serviços. Este programa possui, como um de seus objetivos, avaliar as ações que visem a melhoraria da qualidade, para tanto, se faz necessário profissionais com conhecimentos específicos e bem treinados. Neste caso, de acordo com os resultados aqui apresentados, os serviços públicos tendem a serem vistos pelo cidadão como um serviço de qualidade.

Em suma, a análise destas duas variáveis, X11 e X15, como demonstra a regressão, pode ser um ponto de partida de ações que levem a organização pública a alcançar maior eficiência nos processos, bem como a eficácia dos resultados, resultando em maior qualidade percebida pelo cidadão.

\section{Conclusão}

Os serviços públicos estão disponíveis a todos os cidadãos. Estes, por sua vez, querem receber um serviço de qualidade. Assim, o objetivo, foi identificar o conceito de qualidade que mais influencia a percepção dos usuários quanto à qualidade do serviço público. Ao final das análises concluiu-se que todas as variáveis apresentadas na pesquisa são importantes na percepção do usuário. Como não é possível realizar todas ações pertinentes às variáveis independentes de uma só vez, realizou-se a análise da regressão. Conclui-se desta forma que ter servidores bem treinados e cumprir os princípios da lei, artigo 37 da Constituição Federal a legalidade 
(obediência a lei), a impessoalidade (não fazer acepção de pessoas), a moralidade (valores de aceitação pública), a publicidade (ser transparente) e a eficiência (fazer o que precisa ser feito com a máxima qualidade e menor custo possível) dá ao cidadão uma percepção que o serviço público é de qualidade.

Os resultados desta pesquisa podem auxiliar as organizações públicas a compreenderem a percepção do cidadão quanto à qualidade prestada no serviço público. Serve para os gestores dos órgãos públicos realizarem projetos, delimitarem ações com a finalidade de prestar um serviço público de qualidade sob a perspectiva do cidadão, colocando o cidadão no centro das atenções, que é a finalidade do Programa Nacional de Gestão Pública e Desburocratização Gespública (Brasil,2009).

Para a academia, este estudo contribuiu para a identificação da compreensão do cidadão a respeito da qualidade dos serviços prestados no setor público. Com base nos resultados encontrados, tanto na estatística descritiva quanto na análise dos dados da regressão, o conceito "qualidade como conformação de especificação" foi o melhor compreendido pelos usuários do serviço público.

Como principal limitação encontrada neste estudo é a existência de outras variáveis que podem afetar a percepção do cidadão quanto à qualidade de um serviço público, pois o ajustamento do modelo foi baixo e outras variáveis, não contempladas no estudo, podem formar a percepção do cidadão do que seja um serviço público de qualidade. Outra limitação se refere à amostragem por conveniência, não probabilística, portanto os resultados trazem evidências gerais sobre os serviços públicos. Tais evidências são características de estudos de medidas de percepção, não sendo passível de generalização. Ainda sobre a amostra, ela é genérica e representa uma visão geral do cidadão brasileiro sobre os serviços públicos de maneira geral, sem se ater a características específicas da população e de qualquer tipo de serviço público.

Para comparação dos resultados, sugere-se realizar esta pesquisa de maneira segmentada por região, por idade, por tipo de serviço público, entre outros. Como indicação de continuidade do estudo, uma pesquisa quantitativa com mais variáveis pode explicar melhor as influências sobre a percepção do cidadão a respeito da qualidade em um serviço público. Outra sugestão seria verificar a compreensão dos conceitos de qualidade em países com realidades diferentes em relação à prestação dos serviços públicos.

Por ser a qualidade um tema abrangente, uma importante ferramenta de gestão que afeta a eficiência e a eficácia das organizações, é importante continuar pesquisando o assunto, pois, conforme Reeves e Bednar (1994) surgem diferentes definições de qualidade conforme as circunstâncias.

\section{Referências}

ABREU, Cláudia Buhamra. O comportamento do consumidor diante da promoção de vendas: um estudo da relação preço-qualidade percebida.Revista de Administração de Empresas, v. 34, n. 4, p. 64-73, 1994.

BRASIL. Ministério do Planejamento, Orçamento e Gestão. Programa Nacional de Gestão Pública e Desburocratização - GESPÚBLICA. Documento de Referência. Brasília; MP, SEGES, 2009.

BITNER, Mary Jo. Evaluating service encounters: the effects of physical surroundings and employee responses. the Journal of Marketing, p. 69-82, 1990.

BOLTON, Ruth N.; DREW, James H. A longitudinal analysis of the impact of service changes on customer attitudes. The Journal of Marketing, p. 1-9, 1991. 
CARVALHO, M. S. M. Vieira, TONET, H. Correa. "Qualidade na administração pública”. RAP, RIO DE JANEIRO 28(2): 137-52. ABR./IUN, 1994

CAMPOS, V. Falconi, Qualidade Total - Padronização de Empresas. Ed. EDG. MG 1999.

CORRÊA, Rossi Augusta Alves. Qualidade de Vida, Qualidade do Trabalho, Qualidade do Atendimento Público e Competitividade. Revista Administração Pública - RAP. RJ, 27(1): 11323, jan./mar, 1993

DEMING, E.W. Qualidade: A Revolução da Administração. 1990. Ed. Marques Saraiva. RJ.

DEWHIRST, Frank; MARTINEZ-LORENTE, Angel R.; DALE, Barrie G. TQM in public organisations: an examination of the issues. Managing Service Quality, v. 9, n. 4, p. 265-274, 1999.

ESESP. Escola de Serviço Público do Espírito Santo. Gestão da Melhoria da Qualidade do Atendimento ao Cidadão. SEGER. 2008.

GARVIN, D. A., What Does "Product Quality" Really Mean? (1984) Sloan Management Review. 25-43, Fall,1984

GHOBADIAN, Abby, SPELLER Simon, JONES Matthew. Service Quality Concepts and Models International Journal of Quality \& Reliability Management, Vol. 11 No. 9, 1994, pp. 43-66, (C) MCB University Press, 0265-671X

INOJOSA, Rose Marie, FARRAN Neide. Qualidade em serviços públicos: um caso de mudança. RAP,V.28,4,P.76-9, 1994

HAIR JR., J.F., BABIN, B., MONEY, A. H., SAMOUEL, P., Fundamentos de Métodos de Pesquisa em Administração, Bookman, Porto Alegre, 2005

ISHIKAWA,K. Quality and Standardization: Program for Economic Success, Quality Process, January, p16-20, 1984

MAINARDES, Emerson Wagner; LOURENÇO, Luis; Conceitos de Qualidade: Percepções na Universidade. Tópicos Avançados de Gestão: Reflexões, Contributos e Aplicações. p. 413-428, 2010.

MISOCZKY, Maria Ceci, VIEIRA, Marcelo Milano Falcão. Desempenho e qualidade no campo das organizações públicas: uma reflexão sobre significados. RAP. RJ 35(5): 163-77, SET./OUT, 2001

MWITA, John Isaac. Performance management model. A systems-based approach to public service quality. The International Journal of Public Sector Management, pp. 19-37 Vol. 13 No. 1, 2000,

POLLIT, Christopher. Que es calidad de los servicios públicos. In: Kliksberg, Bernardo (org.). Pobreza: un tema impostergable - nuevas respuestas a nivel mundial. México, Fondo de Cultura Económica, 1993.

——— \& BOUCKAERT, Geert. Defining quality. In: Pollit, Christopher \& Bouchaert, Geert (eds.). Quality improvement in European public services. London, Sage, p. 3-19. 1995.

PARASURAMAN,A., ZEITHAML, Valarie A., BERRY, Leonard L. A Conceptual Model of Service Quality an Its Implications for Future Research. Journal of Marketing. Vol 49. 41-50, 1985

REEVES, C. e BEDNAR, D. "Defining quality: alternatives and implications", The Academy of Management Review, Vol. 19, n 3, pp. 419-445,1994

RODRÍGUEZ, Pablo Gutiérrez et al. The transformation of municipal services: Towards quality in the public sector. Theoretical and Applied Economics, v. 2, n. 2, p. 03, 2009. 
SHARMA, Jyoti. An Expedition to Quality: A Review. The Quality Assurance Journal, v. 13, n. 1-2, p. 113, 2010.

TELLIS, Gerard, J., GAETH, Gary J. Best Value, price-seeking and price aversion: the impact of information and learning on consumer choices. Journal of Marketing, v.54, p.34-45, Apr.1990. 